The Labore Journal of Economics

Special Edition (September 2007)

\title{
Reforming the Government in Pakistan: Rationale, Principles and Proposed Approach
}

\author{
Ishrat Husain"
}

\begin{abstract}
Though government reforms are viewed as important for most developing countries, the rationale for these reforms must be clearly understood if they are to be correctly designed and implemented. From an international perspective, government reforms in Pakistan must be developed to integrate Pakistan into a larger global economy and should be based on the lessons learned from other developing countries. From the domestic perspective, reforms are necessary for the Pakistani government to adapt to the changing domestic environment. The reforms must focus broadly on the Federal, Provincial and District governments, on civil service reform and on business process re-engineering. This paper details the rationale for government reform in Pakistan, focuses on critical areas of reform, and provides a framework for the proposed reform approach.
\end{abstract}

\section{INTRODUCTION}

A legitimate question that is often raised by those working for the government in Pakistan but not by outsiders is: Why reform the Government? Most of them believe that things are going well and the costs of bringing about these reforms will prove to be disruptive for the economy as well as for administration. We had inherited a strong, robust system from the British that has been tried and tested over time and there is hardly any compelling reason to bring about any major structural changes. In order to address this question we have to provide the rationale for bringing about reforms in the government which is done in Section I. Having established the business case for reforms, Section II lays down the principles that would underpin these reforms. Finally, the proposed approach to design the reforms will be discussed in Section III.

\footnotetext{
* Chairman, National Commission for Government Reform, and Former Governor, State Bank of Pakistan.
} 


\section{SECTION I}

\section{Rationale for Reforms}

It must be conceded at the outset that the time horizon for the consummation and impact of the proposed reforms is long term - the next 10 to 20 years and not immediate or short term. The rationale for this plan should therefore be viewed in the context of the long term vision of Pakistan, the external environment in which Pakistan will be operating as a country, the lessons learnt from other successful developing countries, the diagnostic studies including public opinion polls about government performance in Pakistan and the growing expectations of the public at large.

\section{(A) Long Term Vision and External Environment}

Vision 2030 prepared by the Planning Commission in consultation with the private sector, academia, civil society organizations, etc. envisages Pakistan to be a developed, industrialized, just and prosperous nation at the end of the next 20-25 years. This vision is to be achieved through rapid and sustainable development in a resource constrained economy by deploying knowledge inputs. The transition for achieving this objective is proposed to be managed by an intelligent and efficient exploitation of globalization through competitiveness. Pakistan is therefore opting to become an active participant in the globalized economy for goods, labor, capital, technology and services, and this option has serious consequences for the future governance of the country.

The imperative of integrating Pakistan in the larger global economy places certain essential demands and one of these demands is that the structures of the state and instruments of the government have to be redesigned to use knowledge and technology inputs to create opportunities for increased productivity and competitiveness within the constraints imposed by depleting resources. Among the 180 nations of the world which are Pakistan's competitors for capturing market share in the ever expanding global economy, only those will survive that remain agile and adapt themselves to the changing demand patterns, supply value chain and technological upgradation. The main actors in a country that will together impinge upon its competitiveness and productivity are the state, market and civil society. The respective roles of these main actors and their interrelationships have therefore to be redefined and re-calibrated.

Structural economic reforms to improve Pakistan's prospects for competing in the globalized economy require stable, functioning, competent 
and responsive institutions for implementation. But unfortunately, we are at present caught in a difficult logjam. While the economic reforms themselves create dislocation and displacement in the transition period, strong working institutions provide the wherewithal and armory to withstand these shocks thus minimizing the costs of adjustment and maximizing the benefits to the poor and neglected. The urgency to build strong institutions to implement these structural reforms is therefore quite obvious.

Following this logical sequence the various organs of the State executive, judiciary and legislature - have to be assessed and evaluated to determine whether they are capable of meeting this new challenge or whether they need to be re-vamped to develop new capabilities and build up new response capacity. The task assigned to the National Commission for Government Reforms (NCGR) is limited to a review and examination of one of the organs of the State i.e. the Executive branch. The Commission has been asked to assess whether the government, its structures, processes and human resources can keep up with these new demands or need modification or alteration.

\section{(B) Lessons from other Developing Countries}

The role and limitations of governments in various developing countries have been analyzed at great length. The majority view is that governments should do what they are capable of doing better than in the past. A strong and effective government is needed rather than a weak and expansive government. The all wide-encompassing government has become too cumbersome and centralized with overlapping and competing interests, inefficient and unresponsive to the emerging needs of the public. Civil servants are poorly trained, sub-optimally utilized, badly motivated and ingrained with attitudes of indifference and inertia. It has been argued by development economists ${ }^{-1}$ that effective government in developing countries is not only necessary due to abundant market failures but possibly even sufficient to achieve economic development.

A number of developing countries have successfully reformed their governments and tackled the market failures as well as achieved rapid economic development. How have they been able to transform the expansive government into a well focused, well functioning and result oriented effective government? The interpretation of the success of East Asian countries such as the Newly Industrializing Countries (NICs), ASEAN countries and China is a matter of serious debate among development economists. Neoclassical economists attribute the success to market friendly, private led growth and openness to trade with the governments providing 
macroeconomic stability, security of person and property, infrastructure services, promoting research and development, investing in education, health, science and technical training. Others such as Wade (1990) and Amsden (1989) have argued that an interventionist state which guided and steered a proactive industrial policy and picked the winners, was largely responsible for their success. By now, there is some consensus that if the labels and ideologies are set aside, the evidence suggests that countries that have tended to promote competition and avoided monopolies or oligopolies, ensured a level playing field and entry for new comers in the market, made privatized firms face competition, exercised regulatory vigilance (but eliminated inefficient and outdated regulations), opened up the economy to international trade, provided the way for judicial independence, provided dispute resolution mechanisms and enforced contracts, promoted transparency, observed the rule of law, have been relatively successful. In short, the government provided an enabling environment for private businesses to carry out production, distribution, trade of goods and services but did not indulge itself in these activities directly.

The other piece of empirical evidence that is beginning to gain wide acceptance is that decentralization and greater devolution of power, authority and resources to lower tiers of government also makes a difference through better allocation and a more efficient utilization of resources. Devolution also helps in moving towards a relatively more egalitarian outcome in the provision of basic public goods services.

Another way to promote human development and deliver social services to the poor segments of the population that has worked is through the wider participation of the private sector, communities and civil society organizations. Participation, besides being considered a means to further human capabilities a la $\mathrm{Sen}^{-}$is also a way of choosing the right kind of projects and ensuring that development funds are used more judiciously. Private-public partnerships and public-NGO or Civil Society Organization partnerships are being successfully used in many countries for the provision of infrastructure, education, health and other social services. These partnerships not only supplement the limited public resources and counter the governance issues through monitoring, evaluation and corrective actions but also enable local communities to participate in decision making through their organizations. The reduced efficiency of public sector expenditure can also be corrected through these partnerships. 


\section{(C) Changes in Pakistani Scene}

We now turn to the diagnostic studies and the changes that have taken place in the landscape in Pakistan in the past several years and are likely to affect the functioning of the government in the future. A number of commissions, committees, task forces, and working groups have examined and made recommendations about the changes in our administrative system. These recommendations and studies have been scanned and sifted and the proposals that are still relevant and useful will form part of the NCGR's recommendations. But in addition to the historical reasons there have been at least seven new developments in the last few years that clearly point to the need for reforms in the structure, processes and human resource management policies and practices.

First, it is becoming increasingly apparent that the benefits of economic growth have not been distributed equitably among the lower income groups, backward districts, rural areas and women. Although the government has used the channels of devolution and poverty targeted interventions to spread these benefits, the results have been less than satisfactory. Almost all studies point out that the institutions of governance i.e. the governmental machinery at the Federal, Provincial and Local Governments have become largely dysfunctional due to the protracted neglect of our institutions. Almost all comparative country rankings, whether originating from the World Bank* or Global Competitiveness Report of the World Economic Forum or other think tanks and institutions consistently rate Pakistan quite low in Public Sector Management, Institutions and Governance. Along with the low Human Development Indicators this weak institutional dimension makes the task of poverty reduction, income distribution and delivery of public services quite difficult. The impact of good economic policies upon the lower strata of our society, particularly those who are illiterate and are not well connected, thus gets muted. The widespread hue and cry about the absence of a trickle down effect of good economic policies is a manifestation of the dysfunctional nature of our public sector governance. Government institutions have to be strengthened to meet this challenge.

Second, the responsibilities of the government in the field of owning, managing and operating public enterprises and corporations have undergone significant change both in the thinking as well as action during the last sixteen years. A large number of government owned corporations, businesses, industrial units, banks and financial institutions and service providers have either been privatized or are in the process of privatization. This will reduce the burden on the administrative apparatus at all levels of 
government. The shedding of these activities by the government has serious repercussions for the oversight function of the Ministries/ Departments in the post privatization period.

Third, the devolution of administrative, operational and financial powers to local governments since 2001 has introduced a completely new element in the governance structure that will require suitable modifications in other tiers of the government. The Federal Government is seriously considering the transfer of some functions listed in the concurrent list of the constitution to the Provincial Governments. The projected increased award of financial resources to the provinces under the National Finance Commission should provide some fiscal space to them for carrying out essential public services directly or through the District Governments. This implies a reallocation of administrative resources and the strengthening of capacity at the local government level.

Fourth, the unbundling of the policy, regulatory and operational responsibilities of the Federal ministries has shifted the focus on the policy making, monitoring and evaluation functions. But this transition has been incomplete, uneven and mixed across the ministries and needs to be firmly rooted. The lack of adequate competence and knowledge of regulatory functions would demand the development of expertise in this field as well as in policy formulation, implementation and evaluation.

Fifth, some limited success has been achieved by fostering private public partnerships in the fields of infrastructure, education and health. But these partnerships can only be nurtured if the government departments and ministries have the adequate skills to design concession agreements, B.O.T or contractual arrangements, monitoring and evaluation tools and legal recourse to enforce the obligations and stipulations agreed by the private sector partners. Similarly, the NGOs and community organizations such as Rural Support Programs have been actively engaged in the delivery of public services in the fields of education, health, water supply etc. The government departments and ministries have to be reconfigured to develop the capacity to design and operate these partnerships.

Sixth, there is a great deal of uncertainty and anxiety among the members of the civil services of the country about their future career prospects. Those specialists serving in ex-cadre jobs such as scientists, engineers, medical doctors, accountants, etc. are demoralized because they have limited opportunities for career progression. They also feel that they are not treated at par with the cadre service officers in matters of promotion and advancement. 
Seventh, the switch over from manual to automated processes and the government's commitment to move towards E-Government would require a look at the skill mix and training requirements of the existing and future civil servants throughout the entire hierarchy. E-Government will itself flatten the hierarchical texture and make apparent the redundancies in the system. At the same time it will involve basic computer literacy at all levels and grades, digital archiving, storage and retrieval of all files and documents. Consequently, only a few of the clerical and subordinate staff positions can be utilized in the future government organization.

\section{(D) Expectations-Delivery Gap}

The recent political history of South Asia clearly points to the failure of successive governments to live up to the expectations of the majority of their population. This trend has become even more acute in the last decade or so with the advent and spread of the electronic media. Although all the countries in the region have performed well and attained respectable rates of economic growth, yet every incumbent government has been voted out of power at the time of elections. The benefits of growth may have filtered down but the speed and their distribution have not been able to satisfy the electorate. The ICT (Information Communication Technology) revolution that has touched even the remote areas of these countries has, in fact, tended to exaggerate the disparities and contributed to higher expectations of government. On the one hand, the capacity of the government institutions responsible for the delivery of public goods and services has rapidly eroded and is in a debilitating and feeble state, while a large variety of goods and services available, advertised and visually observed on the electronic media has whetted their appetite. They believe that the means through which they can acquire these goods and services for themselves and their children is through public sector employment, education and training and government transfers. In actual practice, the allocation of public goods, services, employment and subsidies is rationed by access to the government functionaries or by paying bribes. As these groups have neither the access nor the money to pay the bribes, they suffer from a relative sense of deprivation while observing that the influential and well-to-do segments of the population are preempting and enjoying the benefits of government jobs, contracts, permits, land, etc. Large, untaxed incomes are also accruing to the same privileged groups and individuals. The resentment of this poor and unconnected population is conveyed through the only instrument they possess i.e. the vote at the time of elections. This gap between expectations and delivery is one of the biggest challenges for Pakistan too. 
The popular perceptions as expressed in public opinion polls, media commentaries and editorials, articles and papers, seminars and discussions, observations of politicians and civil society actors, all convey with a few honorable exceptions, a negative image of the civil servants in Pakistan and a high level of dissatisfaction with the functioning of the Ministries, Departments, Corporations and Agencies of the different tiers of the government. These perceptions are in contrast to the views of the civil servants themselves who see themselves as poorly paid, highly demoralized and stressed out individuals. They feel that they have been unfairly treated by their political bosses and unappreciated by the general public. Empirical studies and casual observations show that the root cause of this disenchantment of civil society and the disillusionment of the civil servants can be traced to structural, procedural and motivational deficiencies in the overall system of governance. Any attempts to treat the symptoms in an isolated manner without coming to grips with the root causes will be counterproductive. The reform package should be comprehensive with a clear blueprint, but the introduction of each set of reforms could be phased and sequenced. The methodology adopted by the NCGR therefore follows with logic.

\section{SECTION II}

\section{Broad Principles Underpinning the Reforms}

In order to lay down the direction in which the reforms will be undertaken, it is essential that the broad principles that will underpin these reforms are clearly defined. The following broad principles are outlined under each area of the reforms.

\section{Civil Services}

i) Open, transparent merit-based recruitment to all levels and grades of public services with regional representation as laid down in the Constitution.

ii) Performance-based promotions and career progression for all public sector employees with compulsory training at post-induction, midcareer and senior management levels.

iii) Equality of opportunities for career advancement to all employees without preferences or reservations for any particular class. 
iv) Replacement of the concept of Superior Services by equality among all cadres and non-cadres of public servants.

v) Grant of a living wage and compensation package including decent retirement benefits to all civil servants.

vi) Strict observance of security of tenure of office for a specified period of time.

vii) Separate cadre of regular Civil Services at the Federal, Provincial and District levels co-existing with contractual appointments.

viii)Creation of an All Pakistan National Executive Service (NES) for senior management positions drawn through a competitive process from the Federal, Provincial and District level Civil Servants and outside professionals.

ix) Introduction of four specialized cadres under the NES for Economic Management, Regulatory, Social Sector Management and General Management.

\section{Structure of Federal, Provincial and District Governments}

a) Devolution of powers, responsibilities and resources from the Federal to the Provincial governments.

b) Establishing inter-governmental structures with adequate authority and powers to formulate and monitor policy formulation.

c) Clear separation of policy making, regulatory and operational responsibilities of the Ministries/Provincial departments.

d) Making each Ministry/Provincial department fully empowered, adequately resourced to take decisions and accountable for results.

e) Streamline, rationalize and transform the attached departments/ autonomous bodies/ subordinate offices/field offices, etc. into fully functional arms of the Ministries for performing operational and executive functions.

f) Reduce the number of layers in the hierarchy of each Ministry/ Provincial department. 
g) Cabinet Secretary to perform the main coordinating role among the Federal Secretaries on the lines of the Chief Secretary in the Provinces.

h) Revival and strengthening of the Secretaries Committee at the Federal/ Provincial governments to become the main vehicle for inter-ministerial coordination and dispute resolution among various ministries.

i) District level officers interacting with the general public in day-today affairs should enjoy adequate powers, authority, status and privileges to be able to resolve the problems and redress the grievances of the citizens.

j) Police, Revenue, Education, Water Supply, and Health are the departments which are highly relevant for the day-to-day lives of the ordinary citizen of this country. The internal governance structures of these departments, public grievance redressal systems against these departments and checks and balances on the discretionary powers of the officials have to be introduced.

\section{Business Process Re-Engineering}

i) All laws, rules, regulations, circulars, and guidelines issued by any government ministry/department/agency should be available in its most up dated version to the general public free of cost in a userfriendly manner on the web page and in electronic and print forms at public places.

ii) Service standards with timelines for each type of service rendered at the District, Thana and Union level should be developed, widely disseminated and posted at public places in each department.

iii) Rules of business of the Federal, Provincial and District government should be revised to make them simple and comprehensible, empowering the Secretaries/Heads of Departments/District Coordination Officers to take decisions without multiple references, clearances and back and forth movement of files. Post-audit of the decisions taken should be used to ensure accountability rather than prior clearances.

iv) Delegation of financial, administrative, procurement, human resource management powers should be revisited and adequate 
powers commensurate with the authority should be delegated at each tier of the hierarchy.

v) Estacode, Financial Rules, Accounting and Audit Rules, Fundamental Rules and all other rules in force should be reviewed systematically and revised to bring them in line with modern management practices.

vi) E-Government should be gradually introduced in a phased manner. Technological solutions, hardware and software applications are easy parts of the process, but the most difficult aspect is the training and change in the culture, attitude and practices. E-Government should be driven by business needs rather than crafted as an elegant technical solution.

\section{SECTION III}

\section{Proposed Approach}

There are several ways to approach the task assigned to this Commission. One option is to spend several years in preparing a comprehensive blueprint and plan for bringing about the desired changes covering all aspects of the structure, processes and human resource policies of government. This option has the disadvantage that by the time the report is ready, ground realities might have changed. Political support for reforms under this approach is most likely to wane as high costs are incurred upfront in pushing through complex, unpopular and difficult decisions, but the benefits of the reforms do not become visible in the lifecycle of the political regime in power. The advantage of this option is that all deficiencies and weaknesses are addressed simultaneously in a comprehensive manner.

The second option is to prepare a long term vision and direction in which reforms should aim and move, but combine this with an opportunistic approach whereby easy to implement changes are taken up first and the more difficult reforms are taken up later. The disadvantage of this option is that the changes introduced may be imperceptible and the time taken for the whole process to complete may be too long. But the advantage is that incremental changes that create a win-win situation for all the stakeholders including politicians have a much better chance of being accepted and implemented. It is suggested that the Commission may propose the second option as the modus operandi for its working. 
The preference for this option which is less elegant and imperfect lies in a dispassionate reading of the past history of reforms in this country. A large number of erudite Commissions and Committees have spent virtually thousands of man years in seeking out views and opinions from a diverse set of opinion makers and public at large, prepared elaborate diagnostic studies and presented a very sensible set of recommendations. But except for some tinkering here and there most of the recommendations were not implemented because of lack of political will and courage. The two exceptions to this trend are:

(a) The Civil Service Act. of 1973 which under the leadership of Mr. Z.A. Bhutto brought an end to the historical covenant between the government and higher civil servants.

(b) The Devolution Plan of 2001 under the leadership of President Musharraf which devolved powers from the Province to Districts.

These radical reforms uprooted the existing structures, processes and relationships but the transition period for their replacement by the new structures, processes and relationships has been quite long. In both these cases there was strong political will, but fierce resistance to these changes was equally strong. Learning from these two examples the second option appears more pragmatic. We have, at present, strong political leadership for the reform of the government and we need to develop a long term framework in which the direction of the reforms is clearly laid down. The movement towards the ultimate goal post will be more nuanced - by applying acceleration when the opportunity presents itself, through a brake or temporary reversal when the resistance is fierce, through second or third gears when the opposition is neutralized and the results achieved pacify the opponents.

The sequencing, phasing and timing of the various reforms and their implementation will be guided by the speed at which consensus is built among the stakeholders and the decisions are made by the top policy makers, but it is important to lay down the overall direction in which these reforms will move.

While the comprehensive reforms will be implemented incrementally, a second track will also be followed in which some quick win reforms will be implemented from time to time as an opportunity presents itself. For this purpose, the Commission will follow a more flexible route. For example, it has decided to focus on four major areas where the 
interaction between the ordinary citizen and administrative machinery of the government is most intense. These four areas are:

1. Police and Enforcement of Laws.

2. Land Revenue Administration

3. Education

4. Health

The Commission has formed four sub-committees to review and examine the efforts being made by the government, private sector and civil society in each of these areas and come up with solutions that will make the existing system more efficient and responsive to the needs of the public in the immediate or short run. The Commission has also formed another subcommittee to recommend revision in the Rules of Business for removing impediments in the functioning of the government departments/ministries/ agencies and empowering the heads of the departments to deliver results.

The preliminary recommendations of the sub-committees will be presented to focus groups of stakeholders drawn from diverse segments of society - secretaries, committees, political leaders, businessmen, NGOs, academically refined civil servants, etc. - to solicit their feedback and views. Once this feedback is incorporated, the sub-committees will finalize their recommendations which will then be discussed by the Commission and then presented for consideration and decisions by the Steering Committee. The high powered Steering Committee is co-chaired by the President and Prime Minister and consists of the four Chief Ministers. The Committee has decided to provide a legal cover to the Commission so that the recommendations approved by the Steering Committee are implemented by the Federal and Provincial governments without further reviews.

The Commission will also act as a facilitator and conduit for the reforms formulated by the Federal Ministries/Provincial Governments and table them, after its own analysis for the decisions by the Steering Committee.

To conclude, those who agree that there is a need for these reforms have serious reservations about their implementation. They contend that these reforms cannot be implemented in the real sense unless we insulate bureaucratic actions from political interference. According to this school of thought, the problem of maladministration 
and poor governance stems from this interference. It must be recognized that in democratic forms of governance, elected leaders will have to respond to their political constituents and the associated vested interests. The accountability for results rests largely on these politicians and not on the civil servants. If the interference of the politicians is aimed at serving the narrow parochial interests of a few individuals or groups rather than the broader collective interests of their constituencies, they may end up paying a heavy price at the time of the next elections. Their opponents, the opposition parties and the media scrutiny will keep a watch on their actions and expose them before their constituents. The alignment of the civil servants with their political bosses in violating or circumventing laid down laws, rules, regulations and procedures would prove to be myopic as these civil servants will also become tainted and suffer in their career advancement. If the successive civil servants appointed to key positions refuse to carry out illegal, unlawful or irregular orders, how many times can a minster get them transferred or how many of them could be appointed as OSDs? The strong temptation to indulge in immediate gratification by keeping the political bosses happy and either ignore or go along with them is indeed the crux of the problem. The long term consequences of succumbing to such temptations should always be kept in mind by this category of civil servants. There is no substitute for personal integrity and character in public service.

However, to expect that we will be able to induct angels in the civil services is also unrealistic. The thrust of the proposed reforms is to limit the discretionary powers of the decision makers, simplify the cumbersome procedures and processes and make them transparent and realign the incentives of the individual civil servants with those of the organization. It is proposed, therefore, that the Commission should remain as a permanent body responsible for changed management in the government, but limit the term of the office of the Chairman and members to two years only. 


\section{References}

Amsden A, 1989, Asia's Next Giant: South Korea and Late Industrialization Oxford: Oxford University Press.

Government of Pakistan, 2007, Vision 2030 Draft, Planning Commission, Islamabad.

Husain I, 1999, The Economy of an Elitist State, Oxford: Oxford University Press.

Kaufmann D and Mastruzzi M, 2005, “Governance Matters IV," World Bank.

Leipzeiger D, 1997, Lessons from East Asia, Ann Arbor: University of Michigan Press.

National Commission for Government Reforms, Concept paper (website www.ncgr.ov.pk_2006.

Sen. A.K. 1999, Development as Freedom, Oxford: Oxford University Press.

Stiglitz J and Yusuf S, 2001, Rethinking the East Asia Miracle, Oxford University Press. Bradhan P and Mookherjee D, 2001, "Decentralization Corruption and Government Accountability: An Overview" in Susan Rose-Ackerman, Handbook of Economic Corruption, Cheltenham: Edward Elgar.

Todaro, M.P and Smith, S.C, 2004, Economic Development, Pearson.

UNDP, 2003, Pakistan National Human Development Report.

Wade R, 1990, Governing the Market: Economic Theory and the Role of Government, Princeton: Princeton University Press.

World Bank, 1993, The East Asia Miracle: Economic Growth and Public Policy, Oxford University Press.

World Development Report 2000/2001, New York: Oxford University Press. 